3. Metlay JP, Waterer GW. Treatment of community-acquired pneumonia during the coronavirus disease 2019 (COVID-19) pandemic. Ann Intern Med 2020 May 7 [E-pub ahead of print]. doi: 10.7326/M20-2189.

4. Vardakas KZ, Matthaiou DK, Falagas ME. Incidence, characteristics and outcomes of patients with severe community acquired-MRSA pneumonia. Eur Respir J 2009;34:1148-1158.

5. Uyeki TM, Bernstein HH, Bradley JS, et al. Clinical practice guidelines by the Infectious Diseases Society of America: 2018 update on diagnosis, treatment, chemoprophylaxis, and institutional outbreak management of seasonal influenza. Clin Infect Dis 2019;68(6):e1-e47. doi: 10.1093/cid/ciy866. [Published correction appears in Clin Infect Dis 2019;68:1790].

6. Carr AL, Daley MJ, Givens Merkel K, Rose DT. Clinical utility of methicillinresistant Staphylococcus aureus nasal screening for antimicrobial stewardship: a review of current literature. Pharmacotherapy 2018;38:1216-1228.
7. Farr AM, Aden B, Weiss D, Nash D, Marx MA. Trends in hospitalization for community-associated methicillin-resistant Staphylococcus aureus in New York City, 1997-2006: data from New York State's Statewide Planning and Research Cooperative System. Infect Control Hosp Epidemiol 2012; 33:725-731.

8. Jones M, Jernigan JA, Evans ME, Roselle GA, Hatfield KM, Samore MH. Vital signs: trends in Staphylococcus aureus infections in Veterans' Affairs Medical Centers-United States, 2005-2017. Morb Mortal Wkly Rep 2019; 68:220-224.

9. Kourtis AP, Hatfield K, Baggs J, et al. Vital signs: epidemiology and recent trends in methicillin-resistant and in methicillin-susceptible Staphylococcus aureus bloodstream infections-United States. Morb Mortal Wkly Rep 2019;68:214-219.

\title{
Asymptomatic coronavirus disease 2019 (COVID-19) in hospitalized patients
}

\author{
Victor C. Passarelli MD ${ }^{1}$ (1), Klinger Faico-Filho MD¹, Luiz V. L. Moreira BSc${ }^{1}$, Luciano Kleber de Souza Luna PhD', \\ Danielle D. Conte $\mathrm{PhD}^{1}$, Clarice Camargo PhD², Ana H. Perosa PhD ${ }^{1}$ and Nancy Bellei Professor, MD, PhD ${ }^{1}$ \\ ${ }^{1}$ Infectious Diseases Division, Department of Medicine, Escola Paulista de Medicina - Universidade Federal de São Paulo, São Paulo, Brazil and ${ }^{2}$ Instituto de \\ Pesquisa PENSI - Sabará Hospital Infantil, São Paulo, Brazil
}

To the Editor-In 1 week, 9 in 120 asymptomatic inpatients (7.5\%) were diagnosed with coronavirus disease 2019 (COVID-19) at a hospital with a universal face mask policy. The median length of stay was 11 days, suggesting nosocomial infections. Most were presymptomatic, with median cycle threshold value of 22 , indicating high viral loads. Assessment of asymptomatic COVID-19 can help determine the true impact of the disease and improve knowledge on transmission potential, which is of paramount relevance for public health policies and for infection control. ${ }^{1,2}$

Between the July 6 and 12,2020, 120 patients aged $>18$ years at São Paulo Hospital in São Paulo, Brazil, were screened for severe acute respiratory coronavirus virus 2 (SARS-CoV-2) with RT-PCR on nasopharyngeal specimens. All patients were assessed for symptoms (including fever $\geq 37.8^{\circ} \mathrm{C}$, cough, anosmia, dysgeusia, dyspnea, myalgia, headache, and nasal discharge), and were asymptomatic at enrollment.

The hospital normally has $\sim 600$ beds, but during the pandemic, this hospital was divided between isolated COVID-19 units with 120 beds and general units with restricted capacity, leaving $\sim 100$ beds to non-COVID-19 patients. The hospital had a universal face mask policy for healthcare staff (surgical), patients, and visitors (cloth or surgical) at the time of sample collection. None of the patients were suspected COVID-19 cases nor had known exposure to confirmed cases, so the standard care for the condition which they were hospitalized was carried out normally for these patients.

Author for correspondence: Victor C. Passarelli, E-mail: vicpassarelli@hotmail.com Cite this article: Passarelli VC, et al. (2021). Asymptomatic coronavirus disease 2019 (COVID-19) in hospitalized patients. Infection Control \& Hospital Epidemiology, 42: 1158-1160, https://doi.org/10.1017/ice.2020.441
Outcomes were monitored until test results were received. If a test was positive, the patient was transferred to an isolated unit. This study was approved by the local ethics committee and all subjects signed a written informed consent form.

Data are summarized as percentages and medians (ranges), and 95\% confidence intervals were calculated via the binomial method using free Statistics version 4.0 software.

\section{Results}

Overall, 9 asymptomatic patients (7.5\%; 95\% CI, 3.48\%-13.76\%) were diagnosed with COVID-19 (Table 1). Two patients (22.2\%) were in the hospital due to surgery, and the others were hospitalized due to clinical conditions. The median time of hospitalization was 11 days (range, 1-39).

All asymptomatic patients with COVID-19 had considerable comorbidities, including hypertension $(\mathrm{n}=7,77.7 \%)$, obesity $(\mathrm{n}=5,55.5 \%)$, and diabetes $(\mathrm{n}=4,44,4 \%)$. Also, 4 patients (44.4\%) had immunocompromising conditions: 2 had rheumatic diseases, 1 had had a kidney transplant, and 1 had a nephrotic syndrome requiring high-doses of corticotherapy.

Notably, 6 patients $(66.7 \%)$ developed respiratory tract symptoms a median of 2 days (range, 1-5) after the sample collection; thus, they were recategorized as presymptomatic at time of testing, and all required respiratory support: 3 patients (50\%) required mechanical ventilation (of these, 2 died and 1 was discharged). The other 3 patients received supplemental oxygen with nasal cannula and 1 of them was discharged. The others are still in the hospital due to their comorbidities. The 3 asymptomatic patients were discharged without complications. The median cycle thresold (Ct) values were 22 (range, 19-37) and 38 (range, 35-39) for the presymptomatic and asymptomatic subgroups, respectively. 
Table 1. In-Hospital Demographic Characteristics and Outcomes for Each Patient

\begin{tabular}{|c|c|c|c|c|c|c|c|}
\hline Patient No. & Age, y & Gender & Initial Cause of Hospitalization & Hospital Accommodation & $\begin{array}{l}\text { Length of Stay } \\
\text { When Tested, } d\end{array}$ & $\begin{array}{l}\text { Time to } \\
\text { Symptom } \\
\text { Onset, d }\end{array}$ & Outcome \\
\hline 1 & 79 & Female & Surgical, hip fracture & First floor, single bedroom & 1 & $\ldots$ & Discharge \\
\hline 2 & 53 & Male & Surgical, aortic dissection & Third floor, single bedroom & 39 & $\ldots$ & Discharge \\
\hline 3 & 50 & Male & Clinical, diabetic ketoacidosis & Third floor, single bedroom & 11 & $\ldots$ & Discharge \\
\hline 4 & 36 & Female & Clinical, relapsing polychondritis & $\begin{array}{l}\text { Third floor, shared bedroom } \\
\text { (with patient 5) }\end{array}$ & 11 & 2 & MV/Death \\
\hline $5^{a}$ & 64 & Female & $\begin{array}{l}\text { Clinical, systemic lupus } \\
\text { erythematosus }\end{array}$ & $\begin{array}{l}\text { Third floor, shared bedroom } \\
\text { (with patient } 4 \text { ) }\end{array}$ & 15 & 3 & SONC/ICU \\
\hline 6 & 81 & Male & Clinical, urinary tract infection & Third floor, single bedroom & 6 & 5 & MV/Discharge \\
\hline 7 & 63 & Male & Clinical, urinary tract infection & $\begin{array}{l}\text { Tenth floor (same ward as } \\
\text { patient 8), single bedroom }\end{array}$ & 21 & 4 & MV/Death \\
\hline 8 & 53 & Female & Clinical, nephrotic syndrome & $\begin{array}{l}\text { Tenth floor (same ward as } \\
\text { patient } 7 \text { ), single bedroom }\end{array}$ & 9 & 1 & $\begin{array}{l}\text { SONC/ } \\
\text { Discharge }\end{array}$ \\
\hline $9^{a}$ & 34 & Male & Clinical, decompensated heart failure & Tenth floor, single bedroom & 2 & 2 & SONC \\
\hline
\end{tabular}

Note. ICU, intensive care unit; MV, mechanical ventilation; SONC, supplemental oxygen with nasal cannula.

apatients with no definitive outcome and still in hospital when this manuscript was written.

\section{Discussion}

Most asymptomatic infections were detected in patients who had been in the hospital for longer than the median incubation period for SARS-CoV-2, ${ }^{2}$ which suggests nosocomial transmissions.

Considering potential exposure factors, patients 4 and 5 had shared a 2-bed room for at least 72 hours before they received positive test results from samples taken on the same day (Table 1). Notably, they were also among 5 others (patients 2-6) from this cohort who were on the same hospital floor when diagnosed. Despite their allocation to different wards, the same hospital staff circulate through all wards on a daily basis, suggesting a cluster. ${ }^{2,3}$

Our findings also suggest the underestimated potential of visitor contribution to viral spread in healthcare facilities. Patient 7 had received visits from his wife, who was asymptomatic and wore a face mask at the time, but a few days afterward developed symptoms and was indeed positive for SARS-CoV-2; therefore, she is retrospectively considered a possible source of exposure. Notwithstanding, patients 7 and 8 had been in the same ward for the previous 9 days and were diagnosed at the same time, regardless of being in different single bedrooms and using protective measures; we considered this to be another possible cluster.

Other factors might have imposed higher risk for these possible nosocomial transmissions. Universal masking may induce a false perception of protection that leads to neglect of other important protective measures, ${ }^{4}$ including social distancing and avoiding skin contact. ${ }^{5}$ The incorrect use of full protective personal equipment is also concerning, including inadequate hand hygien ${ }^{6}$ or even the incorrect use of masks due to malpositioning, inadequate fabric materials, or inappropriate reuse. Scarce resources also play a part in nosocomial risk of transmission. ${ }^{7}$

Nevertheless, asymptomatic individuals, including patients and their visitors, may need to be considered when designing strategies to prevent outbreaks in the healthcare setting, regardless of a universal masking policy.

Finally, previous studies have suggested that only a small fraction of asymptomatic persons may eventually develop symptoms, ${ }^{1-3,5}$ but more than half of the initially asymptomatic patients in this study became symptomatic. Perhaps disruption of viral control seen in immunocompromising conditions from the presymptomatic subgroup influenced higher viral loads, ${ }^{8}$ demonstrated by the lower Ct values. ${ }^{9}$ However, previous reports have suggested similar potential for viral transmission in otherwise healthy, presymptomatic subjects as well, ${ }^{3,5,10}$ so it does raise concerns.

The inclusion of healthcare staff and visitors in the screening process could help improve knowledge on viral dynamics in this setting.

In summary, surveillance of asymptomatic COVID-19 in the healthcare setting may be an important measure in reducing nosocomial infections despite universal use of face masks, especially because presymptomatic patients may have high viral loads, suggesting the potential for transmission.

\section{Acknowledgments.}

Financial support. We received support for this report from the Coordination for the Improvement of Higher Education Personnel (CAPES) and the National Council for Scientific and Technological Development (CNPq). No financial grants were received for the research, authorship, or publication of this work.

Conflicts of interest. All authors declare no conflicts of interest related to this work.

\section{References}

1. Oran DP, Topol EJ. Prevalence of asymptomatic SARS-CoV-2 infection. Ann Intern Med 2020 [Epub ahead of print]. doi: 10.7326/m20-3012.

2. Al-Sadeq D, Nasrallah G. The incidence of the novel coronavirus SARSCoV-2 among asymptomatic patients: a systematic review. Int $J$ Infect Dis 2020 [E-pub ahead of print]. doi: 10.1016/j.ijid.2020.06.098.

3. Arons MM, Hatfield KM, Reddy SC, et al. Public Health-Seattle and King County and CDC COVID-19 investigation team. Presymptomatic SARS$\mathrm{CoV}-2$ infections and transmission in a skilled nursing facility. $N$ Engl $J$ Med 2020;382:2081-2090.

4. Howard J, Huang A, Li Z, Tufekci Z, Zdimal V, van der Westhuizen H. Face masks against COVID-19: an evidence review. Preprints 2020. doi: 10. 20944/preprints202004.0203.v1. 
5. Hijnen D, Marzano A, Eyerich K, et al. SARS-CoV-2 transmission from presymptomatic meeting attendee, Germany. Emerg Infect Dis 2020;26:1935-1937.

6. Clinical questions about COVID-19: questions and answers. Centers for Disease Control and Prevention website. https:/www.cdc.gov/coronavirus/ 2019-ncov/hcp/faq.html. Published 2020. Accessed August 25, 2020.

7. VM Dato, Hostler D, Hahn ME, Simple respiratory mask. Emerg Infect Dis 2006;12:1033-1034.

8. Uematsu J, Sakai SK, Kihira NS, et al. Inhibitions of human parainfluenza virus type 2 replication by ribavirin and mycophenolate mofetil are restored by guanosine and S-(4-nitrobenzyl)-6-thioinosine. Drug Discov Ther 2019;13:314-321.

9. Bullard J, Dust K, Funk D, et al. Predicting infectious SARS-CoV-2 from diagnostic samples. Clin Infect Dis 2020 [E-pub ahead of print]. doi: 10 . 1093/cid/ciaa638.

10. Huang C, Wang Y, Li X, Ren L, Zhao J, Hu Y, et al. Clinical features of patients infected with 2019 novel coronavirus in Wuhan, China. Lancet 2020;395:497-506.

\title{
Characterizing coinfection in children with COVID-19: A dual center retrospective analysis
}

\author{
David D. Zhang $M D^{1}{ }^{10}$, Mary Ellen Acree $M D^{2}$, Jessica P. Ridgway $M^{3}$, Nirav Shah MD, $M P^{2}$, Aniruddha Hazra MD $^{3}$, \\ Urmila Ravichandran $\mathrm{MS}^{2}$ and Madan Kumar $\mathrm{DO}^{1}$ \\ ${ }^{1}$ Department of Pediatrics, Section of Pediatric Infectious Disease, University of Chicago Medicine, Chicago, Illinois, ${ }^{2}$ Division of Infectious Disease, NorthShore \\ University HealthSystem, Evanston, Illinois and ${ }^{3}$ Department of Medicine, Section of Infectious Disease and Global Health, University of Chicago Medicine, \\ Chicago, IL
}

To the Editor-Understanding the prevalence of coinfections with coronavirus disease 2019 (COVID-19) is crucial to delineating its true clinical impact. Numerous studies have evaluated coinfections in adults with COVID-19, ${ }^{1-3}$ but data on pediatric COVID-19 coinfections are limited. Here, we evaluate the burden of coinfections in pediatric COVID-19 patients at 2 large Chicagoland medical centers.

\section{Methods}

We retrospectively reviewed electronic health records of all pediatric patients tested for severe acute respiratory coronavirus virus 2 (SARS-CoV-2) from March 9, 2020, through April 30, 2020, in 2 Chicagoland medical centers. At the University of Chicago Medicine, SARS-CoV-2 was diagnosed using one of the following real-time reverse transcriptase polymerase chain reaction (RT-PCR) assays on respiratory specimens: Cobas SARS-CoV-2 RT-PCR assay (Roche Basel, Switzerland) or Xpert Xpress SARS-CoV-2 test (Cepheid, Sunnyvale, CA). Respiratory coinfections were primarily identified using a multiplex RT-PCR respiratory viral panel (RVP) with the following targets: adenovirus, coronavirus 229E/HKU1/NL63/OC43, human metapneumovirus, influenza-A/-B, parainfluenzas 1-4, respiratory syncytial virus, Mycoplasma pneumoniae, Chlamydophila pneumoniae, Bordetella pertussis, and rhinovirus/enterovirus (FilmArray Respiratory Panel, BioFire Diagnostics, Salt Lake City, UT). Coinfections were also identified using the influenza/respiratory syncytial virus (RSV) RT-PCR assay (Cepheid Xpert Xpress Flu/RSV) known as

Author for correspondence: David D. Zhang, MD, Pediatric Infectious Disease, University of Chicago Medicine, 5837 S. Maryland Ave, MC 6054, Chicago, IL 60637. E-mail: David.zhang2@uchospitals.edu

Cite this article: Zhang DD, et al. (2021). Characterizing coinfection in children with COVID-19: A dual center retrospective analysis. Infection Control \& Hospital Epidemiology, 42: 1160-1162, https://doi.org/10.1017/ice.2020.1221 the influenza/RSV panel (IRP). At NorthShore University HealthSystem, SARS-CoV-2 was identified similarly using RT-PCR: Xpert Xpress or BD Max (Becton Dickinson, Franklin Lakes, NJ). Coinfections were detected using a multiplex RT-PCR panel that contained only the viral targets of the RVP (GenMark Dx, GenMark Diagnostics, Carlsbad, CA), as well as an IRP (Roche Cobas Liat Influenza $\mathrm{A} / \mathrm{B}$ and RSV). We included all RVPs and IRPs that were obtained within 7 days of a SARS-CoV-2 test.

We also reviewed antibiotic prescriptions within 7 days of a positive SARS-CoV-2 RT-PCR result, and we evaluated antibiotic indication to confirm whether bacterial coinfection was present. Combined means, frequencies, and standard deviations were calculated from the 2 subgroups of data. The Fisher exact test was used to detect any significant differences in proportions of coinfection between the SARS-CoV-2 positive and negative groups. Statistical significance was defined as $P<.05$. Stata version 16 software (StataCorp, College Station, TX) was used for all analyses.

\section{Results}

During the study period, 3,669 specimens were sent for SARS-CoV-2 testing, and 862 of these $(23.4 \%)$ were positive. Furthermore, 767 (20.9\%) specimens had a paired RVP or IRP within 7 days. Of these paired specimens, 101 (13.2\%) were positive for SARS-CoV-2. The average ages of our aggregate pediatric COVID cohort and the coinfected subgroup were 17.1 years (standard deviation 5.79) and 17 years (standard deviation, 5.11), respectively.

Analyses between RSV/influenza and the rest of the respiratory viral pathogen panel were conducted separately given the large number of IRPs performed (ie, 351 total multiplex RVPs and 424 total $\mathrm{RSV} /$ influenza IRPs). Only 2 paired specimens containing the RVP (12.5\%) tested positive for SARS-CoV-2 and an additional respiratory pathogen (Table 1). In 1 of these 2 patients, 2 viral pathogens on the RVP (rhino/enterovirus and adenovirus) were detected. Of those who tested negative for SARS-CoV-2 who had the RVP, 130 (38.8\%) tested

(c) 2020 by The Society for Healthcare Epidemiology of America. All rights reserved. This is an Open Access article, distributed under the terms of the Creative Commons Attribution licence (http://creativecommons.org/licenses/by/4.0/), which permits unrestricted re-use, distribution, and reproduction in any medium, provided the original work is properly cited. 